\title{
Treadmill Exercise Training Improves Vascular Endothelial Growth Factor Expression in the Cardiac Muscle of Type I Diabetic Rats
}

\author{
Nour S. Erekat ${ }^{\mathrm{a}}$, Muhammed D. Al-Jarrah ${ }^{\mathrm{b}, \mathrm{d}}$, Ahed J. Al Khatib
}

\begin{abstract}
Background: Vascular endothelial growth factor (VEGF) expression is a potent mitogen for endothelial cells that is involved in angiogenesis. Cardiac VEGF is decreased in many pathologic conditions, including diabetes mellitus and aging. Exercise training has improved VEGF expression in the aging heart. Thus, the aim of our study is to illustrate the impact of treadmill exercise training on the cardiac VEGF expression in type I diabetic rats.
\end{abstract}

Methods: Twenty normal Sprague-Dawley rats and Sprague-Dawley rats with streptozotocin-induced diabetes were divided into the following equal groups: sedentary control (SC), exercised control (EC), sedentary diabetic rats (SD) and exercised diabetic rats (ED). Immunohistochemistry was used to investigate VEGF expression in the cardiac tissue in each of the four different groups.

Results: Cardiac VEGF expression was significantly $(\mathrm{P}<0.05)$ lower in SD compared with that in SC. However, exercise training significantly $(\mathrm{P}<0.01)$ enhanced VEGF expression in the cardiac tissue in ED compared with that in SD.

Conclusion: Our present data suggest that treadmill exercise training improved diabetes-induced downregulation in the cardiac VEGF expression.

Keywords: Type I diabetes; VEGF; Cardiac muscle

\footnotetext{
Manuscript accepted for publication December 31, 2013

${ }^{\mathrm{a}}$ Department of Anatomy, Faculty of Medicine, Jordan University of Science and Technology (JUST), Irbid, Jordan

${ }^{\mathrm{b}}$ Department of Rehabilitation Sciences, Faculty of Applied Medical Sciences, JUST, Irbid, Jordan

${ }^{\mathrm{c}}$ Department of Pathology, Faculty of Medicine, JUST, Irbid, Jordan

${ }^{\mathrm{d}}$ Corresponding author: Muhammed Al-Jarrah, Department of

Rehabilitation Sciences, Faculty of Applied Medical sciences, Jordan

University of Science and Technology, 22110 P. O box 3030, Irbid,

Jordan. Email: jarrahm@just.edu.jo. In a leave to: Fatima College of

Health Sciences (FCHS), Abu Dhabi, UAE.

Email: muhammed.aljarrah@fchs.ac.ae
}

doi: http://dx.doi.org/10.14740/cr314w

\section{Introduction}

Vascular endothelial growth factor (VEGF) is a potent mitogen for endothelial cells that is involved in blood vessel formation, a process called angiogenesis [1-4]. VEGF is also involved in vasodilation and antiapoptosis [5-10]. Alterations in VEGF expression have been demonstrated in many pathologic conditions $[11,12]$. For instance, although VEGF upregulation has been shown in Parkinson disease substantia nigra and in the diabetic retinal and renal tissues [13-22], its downregulation has been demonstrated in diabetic skeletal muscle [23-25].

VEGF has been implicated in the pathogenesis of many heart diseases, such as coronary artery disease, ischemic heart disease and strokes [11, 26-29]. Diabetes mellitus is a major risk factor for cardiovascular disorders, including coronary heart disease, stroke, peripheral arterial disease and cardiomyopathy. Such cardiovascular complications significantly increase the risk for morbidity and mortality in diabetic patients [30-35]. Decreased VEGF level has been reported in diabetic cardiac tissue and it has been suggested to cause the impaired collateral formation, which is probably accounting for the increased risk for morbidity and mortality in patients with diabetes mellitus [36-39]. Furthermore, normalization of the downregulated myocardial VEGF level is suggested to improve cardiac dysfunction in diabetes [40].

Exercise training has been shown to exert beneficial effect on VEGF expression in pathologic conditions [23, $41,42]$. For example, downregulated VEGF in the skeletal muscle of diabetic patients was enhanced by exercise training [23]. Similarly, exercise training could improve the decreased level of VEGF in the aging heart [41]. Moreover, treadmill exercise has increased the expression of VEGF in the brain of chronic Parkinsonian mice [42].

To our knowledge, the impact of treadmill exercise training on VEGF expression has never been investigated in diabetic cardiac tissue. Therefore, using immunohistochemistry and light microscopy, the purpose of this study was to examine the effect of treadmill exercise training on VEGF expression in the heart from rats with streptozotocin-induced diabetes mellitus. 

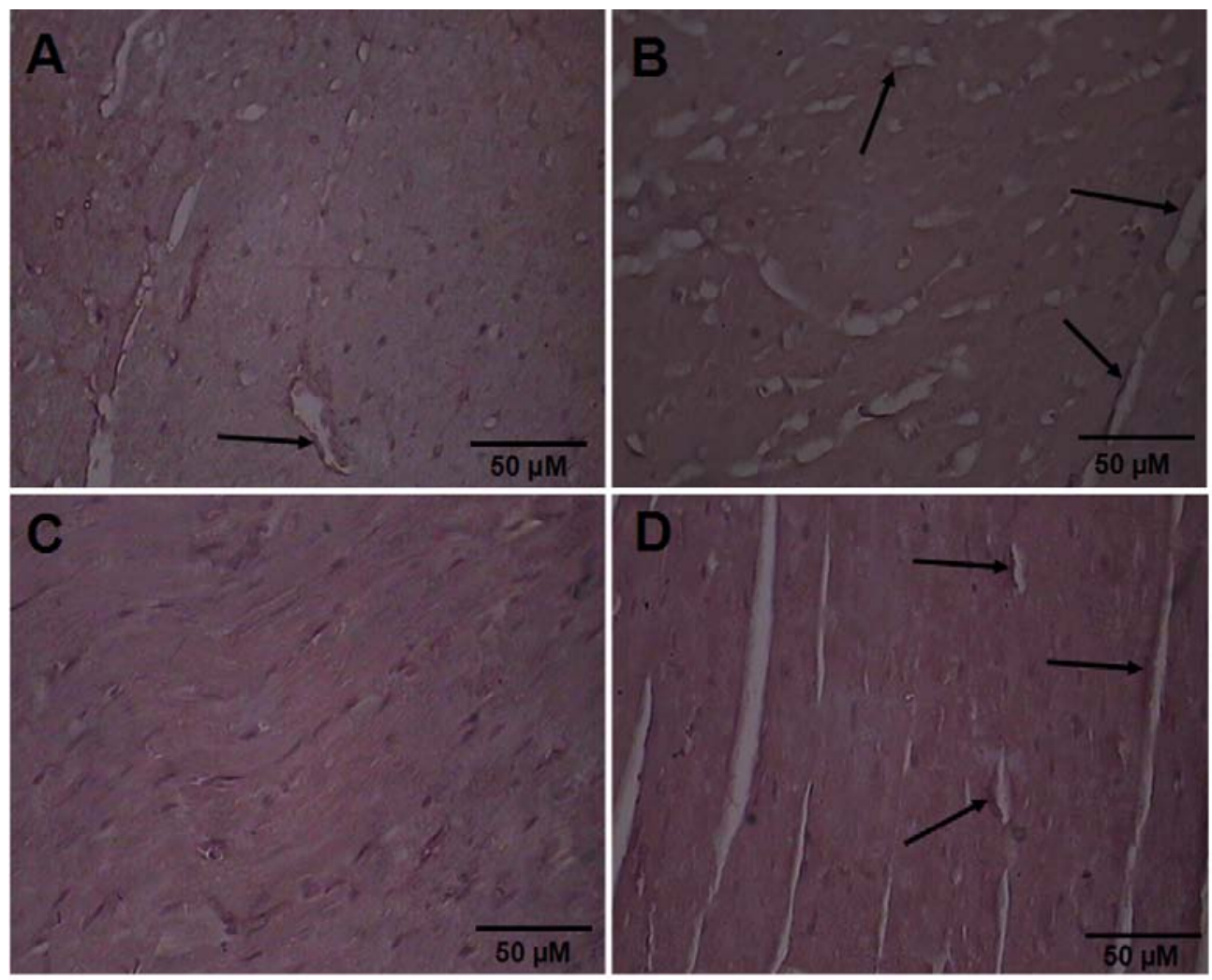

Figure 1. Immunohistochemical staining of VEGF cardiac tissue $5 \mu \mathrm{m}$ thick paraffin-embedded sections. VEGF immunoreactivity (at the tips of the arrows) is stronger following exercise training in the diabetic rats. A) From SC. B) From EC. C) From SPD. D) From EPD. SC: Sedentary Control. EC: Exercised Control. SD: Sedentary diabetic. ED: Exercised diabetic.

\section{Materials and Methods}

\begin{abstract}
Animals
Forty Sprague-Dawley rats were used in this study and randomly divided into four equal groups. Sedentary control $(\mathrm{SC}, \mathrm{n}=10)$, exercised control $(\mathrm{EC}, \mathrm{n}=10)$, sedentary diabetic $(\mathrm{SD}, \mathrm{n}=10)$ and exercised diabetic $(\mathrm{ED}, \mathrm{n}=10)$. Animals were housed in individual cages at $22 \pm 1{ }^{\circ} \mathrm{C}$ in a controlled room with a 12:12 light:dark cycle. The animals were allowed free access to standard chow and water. Animal care and experiments were performed in accordance with the research committee guidelines for animal experimentation at Jordan University of Science and Technology. Alloxan (120 $\mathrm{mg} / \mathrm{kg}$ ) was intraperitoneally injected in the rats in the two diabetic groups. Simultaneously, intraperitoneal saline (120 $\mathrm{mg} / \mathrm{kg}$ ) injections were given to the rats in the two control groups. Three days later, successful induction of diabetes was confirmed by detecting hyperglycemia in the rats, which had fasting blood glucose above $250 \mathrm{mg} / \mathrm{dL}$.
\end{abstract}

\section{Exercise protocol}

The rats were exercised according to the exercise training protocol previously described and suggested to provide adequate systemic and cellular adaptations with this level of aerobic exercise [43]. Briefly, using a custom tredmill with 8 separate lanes, rats in the two exercised, both control and diabetic, groups were running at a speed of $18 \mathrm{~m} / \mathrm{min}, 40$ $\mathrm{min} /$ day for 5 days/week. Although sedentary rats did not exercise, they were transported daily to the training room, in order to expose them to the same environment as the exercised groups of animals.

\section{Immunohistochemistry of VEGF in the heart}

Tissues were collected from the left ventricle of the heart and fixed in $4 \%$ paraformaldehyde. Then, $5 \mu \mathrm{m}$ thick paraffinembedded sections were prepared. After that, the sections were processed via immunohistochemistry according to the protocol described previously [42]. Briefly, the sections were deparaffinized in xylene for 2 minutes twice, and subsequently rehydrated through consecutively descending dilutions of alcohol $(100 \%, 90 \%, 80 \%$ and $70 \%)$ ending in water ( 2 minutes each step). After that, the sections were treated in the reveal solution (RV1000M, Biocare Medical, Concord, $\mathrm{CA}$ ) in the Decloaking chamber (Biocare Medical) for 2 minutes. After cooling sections down to room temperature, 


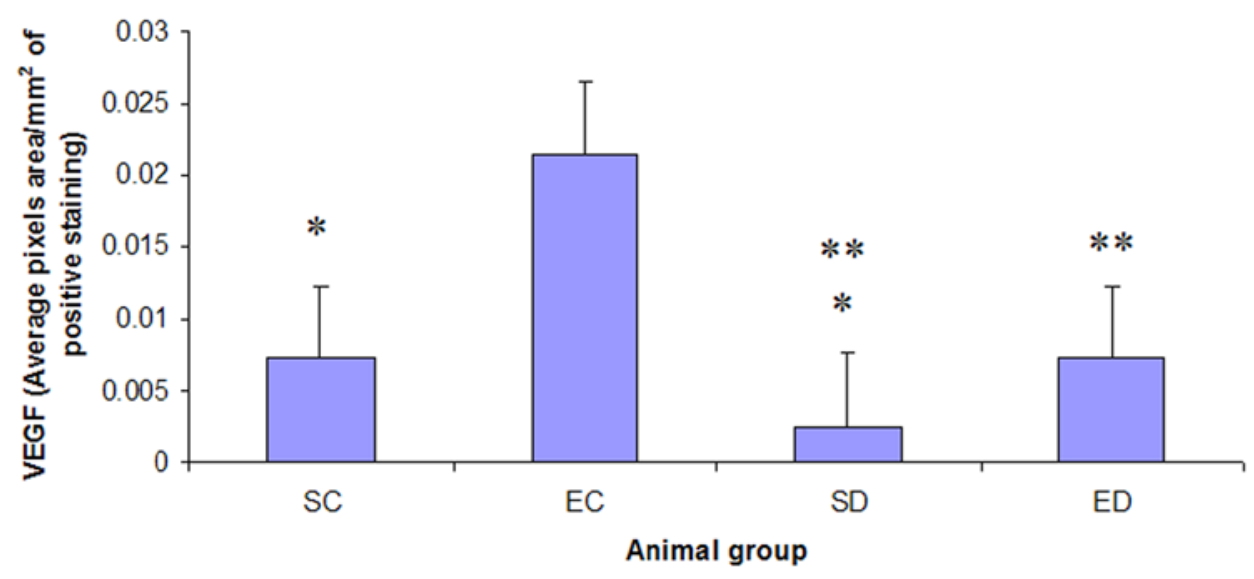

Figure 2. Expression of VEGF in the cardiac muscle. The expression level of VEGF decreased significantly in the diabetic sedentary group compared to sedentary control groups $\left(P<0.05^{*}\right)$. Exercise training significantly increased the expression level of VEGF in diabetic rats $\left(P<0.01^{\star \star}\right)$. SC: Sedentary Control. EC: Exercised Control. SD: Sedentary Diabetic. ED: Exercised Diabetic.

endogenous peroxidase activity was blocked by incubating the sections with $3 \%$ hydrogen peroxide in methanol for 5 minutes. After washing the sections in phosphate buffered saline (PBS), they were incubated with anti-VEGF antibody (Santa Cruz Biotechnology, Santa Cruz, CA), diluted according to vendor instructions, for 1 hour at room temperature. Subsequently, sections were washed in PBS and incubated with biotinylated secondary antibody (LSAB kit, Dako Carpinteria, CA) for 15 minutes at room temperature, then washed with PBS. Sections were incubated with streptavidin horse radish peroxidase (LSAB kit, Dako) for 15 minutes at room temperature and washed with PBS. Finally, 3, 3'-Diaminobenzidine (DAB) substrate was applied for 2 minutes or longer, until the desired color intensity was developed, and then the slides were washed with tap water to stop the reaction. Negative control slides were processed without the primary antibody. All sections were counterstained with hematoxylin and viewed under the light microscopy. Ten slides from each animal group were evaluated for VEGF expression in the left ventricle.

\section{Data collection and analysis}

The sections were photographed with digital camera. Ten slides from each animal of all 10 animals in each of the 4 groups were analyzed by counting the total pixels area occupied by positive staining, using Adobe Photoshop software, as described previously $[42,44]$. VEGF expression was analyzed, in the cardiac tissue from the different groups, and statistically compared among the 4 different groups using one way ANOVA followed by independent sample t-test. Differences in VEGF expression were considered statistically significant at $\mathrm{P}$ value $<0.05$.

\section{Results}

Immunohistochemical staining revealed that there was evidence of VEGF in control hearts (Fig. 1A). Moreover, VEGF immunoreactivity was found in the heart from exercised controls (Fig. 1B). On the other hand, immunohistochemical staining barely showed VEGF expression in diabetic heart (Fig. 1C). In contrast, VEGF immunoreactivity was observed in the hearts from exercised diabetic rats (Fig. 1D).

VEGF expression in the diabetic heart is statistically significantly lower $(\mathrm{P}<0.05)$ than in that in the control heart (Fig. 2). However, treadmill exercise training has statistically insignificantly increased $(\mathrm{P}>0.05)$ cardiac VEGF expression in the control group (Fig. 2). On the other hand, cardiac VEGF expression is statistically significantly increased $(\mathrm{P}<$ $0.01)$ in the exercised diabetic group when compared with that in the sedentary diabetic group (Fig. 2).

\section{Discussion}

This is the first study to report the impact of treadmill exercise training on VEGF expression in the heart of rats with streptozotocin-induced diabetes mellitus. Our analysis reveals that treadmill exercise training upregulated VEGF expression in the cardiac muscle of diabetic rats.

We could detect VEGF in the heart of control rats (Fig. 2). VEGF has been shown to be expressed in the normal heart [45]. VEGF mediates angiogenesis in both physiologic and pathologic conditions [1, 45-47]. Besides, VEGF has many endothelial cell actions relating to permeability, vasodilation and antiapoptosis [5-10, 48-53]. Our results reveal a statistically insignificant increase in the VEGF expression in 
the cardiac muscle of the controls following treadmill exercise training (Fig. 2). Thus, our study confirms the previous report demonstrating insignificant change in VEGF mRNA and protein in the heart from normal rats in response to exercise $[54,55]$. On the other hand, VEGF protein expression was shown to significantly increase 1 day after exercise training in intact mice and gradually return to baseline after 4 days [56].

The present study suggests that the induction of diabetes mellitus by streptozotocin has decreased the expression of VEGF in the heart (Fig. 2). Our results are consistent with the previous reports, which have shown VEGF downregulation in the heart in diabetic and insulin-resistant states and assumed the loss of insulin-induced VEGF expression as the underlying mechanism $[36,57,58]$. In addition to that, those previous reports have suggested decreased level of cardiac VEGF and the consequent inadequate collateral formation as a potential molecular explanation for the increased risk of cardiovascular morbidity and mortality in patients with insulin resistance and diabetes [36, 40, 59].

Exercise has been suggested to have a beneficial role on the risk of coronary heart diseases in diabetic patients [60]. To examine the mechanism by which exercise ameliorates cardiovascular outcome in diabetics, we investigated the effect of treadmill exercise training on the cardiac VEGF expression in rats with streptozotocin-induced diabetes mellitus. Downregulation of VEGF expression has been demonstrated in the aging heart [41]. However, VEGF expression has been improved in the aging heart following endurance exercise training [41]. Similarly, our results (Fig. 2) reveal elevated cardiac VEGF levels in rats with streptozotocin-induced diabetes mellitus following treadmill exercise training. The elevated level of cardiac VEGF, shown by our study (Fig. 2), may explain the increased collateral development and improved endothelial vasodilation in the diabetic heart following exercise training demonstrated in previous studies [61-64].

In conclusion, this is the first study to report the impact of treadmill exercise training on VEGF expression in heart from rats with streptozotocin-induced diabetes mellitus. In summary, treadmill exercise training improves streptozotocin-induced diabetes mellitus-induced downregulation of VEGF expression in the heart.

\section{Acknowledgement}

This study was financially supported by The Deanship of Research at Jordan University of Science and Technology, Irbid, Jordan.

\section{References}

1. Hoeben A, Landuyt B, Highley MS, Wildiers H,
Van Oosterom AT, De Bruijn EA. Vascular endothelial growth factor and angiogenesis. Pharmacol Rev. 2004;56(4):549-580.

2. Simons M. Angiogenesis: where do we stand now? Circulation. 2005;111(12):1556-1566.

3. Tirziu D, Simons M. Angiogenesis in the human heart: gene and cell therapy. Angiogenesis. 2005;8(3):241251 .

4. Tahergorabi Z, Khazaei M. A review on angiogenesis and its assays. Iran J Basic Med Sci. 2012;15(6):11101126.

5. Janvier A, Nadeau S, Baribeau J, Perreault T. Role of vascular endothelial growth factor receptor 1 and vascular endothelial growth factor receptor 2 in the vasodilator response to vascular endothelial growth factor in the neonatal piglet lung. Crit Care Med. 2005;33(4):860866.

6. Fogarty JA, Muller-Delp JM, Delp MD, Mattox ML, Laughlin MH, Parker JL. Exercise training enhances vasodilation responses to vascular endothelial growth factor in porcine coronary arterioles exposed to chronic coronary occlusion. Circulation. 2004;109(5):664-670.

7. Thijs AM, van Herpen CM, Sweep FC, Geurts-Moespot A, Smits P, van der Graaf WT, Rongen GA. Role of endogenous vascular endothelial growth factor in endothelium-dependent vasodilation in humans. Hypertension. 2013;61(5):1060-1065.

8. Morales E, Caro J. Reply to vascular endothelial growth factor: a novel potential therapeutic target for hypertension. J Clin Hypertens (Greenwich). 2013;15(7):515.

9. Religa P, Cao R, Religa D, Xue Y, Bogdanovic N, Westaway D, Marti HH, et al. VEGF significantly restores impaired memory behavior in Alzheimer's mice by improvement of vascular survival. Sci Rep. 2013;3:2053.

10. Won YW, Lee M, Kim HA, Nam K, Bull DA, Kim SW. Synergistically combined gene delivery for enhanced VEGF secretion and antiapoptosis. Mol Pharm. 2013;10(10):3676-3683.

11. Khurana R, Simons M, Martin JF, Zachary IC. Role of angiogenesis in cardiovascular disease: a critical appraisal. Circulation. 2005;112(12):1813-1824.

12. Simons M. Angiogenesis, arteriogenesis, and diabetes: paradigm reassessed? J Am Coll Cardiol. 2005;46(5):835-837.

13. Sen S, Chen S, Feng B, Iglarz M, Chakrabarti S. Renal, retinal and cardiac changes in type 2 diabetes are attenuated by macitentan, a dual endothelin receptor antagonist. Life Sci. 2012;91(13-14):658-668.

14. Cha DR, Kang YS, Han SY, Jee YH, Han KH, Han JY, Kim YS, et al. Vascular endothelial growth factor is increased during early stage of diabetic nephropathy in type II diabetic rats. J Endocrinol. 2004;183(1):183194.

15. Pe'er J, Folberg R, Itin A, Gnessin H, Hemo I, Keshet E. 
Upregulated expression of vascular endothelial growth factor in proliferative diabetic retinopathy. Br J Ophthalmol. 1996;80(3):241-245.

16. Wang J, Xu X, Elliott MH, Zhu M, Le YZ. Muller cell-derived VEGF is essential for diabetes-induced retinal inflammation and vascular leakage. Diabetes. 2010;59(9):2297-2305.

17. Gupta N, Mansoor S, Sharma A, Sapkal A, Sheth J, Falatoonzadeh P, Kuppermann B, et al. Diabetic retinopathy and VEGF. Open Ophthalmol J. 2013;7:4-10.

18. Hammes HP, Lin J, Bretzel RG, Brownlee M, Breier G. Upregulation of the vascular endothelial growth factor/ vascular endothelial growth factor receptor system in experimental background diabetic retinopathy of the rat. Diabetes. 1998;47(3):401-406.

19. Segawa Y, Shirao Y, Yamagishi S, Higashide T, Kobayashi M, Katsuno K, Iyobe A, et al. Upregulation of retinal vascular endothelial growth factor mRNAs in spontaneously diabetic rats without ophthalmoscopic retinopathy. A possible participation of advanced glycation end products in the development of the early phase of diabetic retinopathy. Ophthalmic Res. 1998;30(6):333-339.

20. Lin CL, Wang FS, Hsu YC, Chen CN, Tseng MJ, Saleem MA, Chang PJ, et al. Modulation of notch-1 signaling alleviates vascular endothelial growth factor-mediated diabetic nephropathy. Diabetes. 2010;59(8):1915-1925.

21. Cooper ME, Vranes D, Youssef S, Stacker SA, Cox AJ, Rizkalla B, Casley DJ, et al. Increased renal expression of vascular endothelial growth factor (VEGF) and its receptor VEGFR-2 in experimental diabetes. Diabetes. 1999;48(11):2229-2239.

22. Chen ZJ, Yang YB, Huang SM. [Expression of VEGF in kidney of diabetic rats]. Sichuan Da Xue Xue Bao Yi Xue Ban. 2007;38(4):633-636.

23. Kivela R, Silvennoinen M, Touvra AM, Lehti TM, Kainulainen H, Vihko V. Effects of experimental type 1 diabetes and exercise training on angiogenic gene expression and capillarization in skeletal muscle. FASEB J. 2006;20(9):1570-1572.

24. Bonner JS, Lantier L, Hasenour CM, James FD, Bracy DP, Wasserman DH. Muscle-specific vascular endothelial growth factor deletion induces muscle capillary rarefaction creating muscle insulin resistance. Diabetes. 2013;62(2):572-580.

25. Kivela R, Silvennoinen M, Lehti M, Jalava S, Vihko V, Kainulainen H. Exercise-induced expression of angiogenic growth factors in skeletal muscle and in capillaries of healthy and diabetic mice. Cardiovasc Diabetol. 2008;7:13.

26. Wolf M, Hubel CA, Lam C, Sampson M, Ecker JL, Ness RB, Rajakumar A, et al. Preeclampsia and future cardiovascular disease: potential role of altered angiogenesis and insulin resistance. J Clin Endocrinol Metab. 2004;89(12):6239-6243.
27. Weis SM, Cheresh DA. Pathophysiological consequences of VEGF-induced vascular permeability. Nature. 2005;437(7058):497-504.

28. Petrovic D. The role of vascular endothelial growth factor gene as the genetic marker of atherothrombotic disorders and in the gene therapy of coronary artery disease. Cardiovasc Hematol Agents Med Chem. 2010;8(1):4754.

29. Rasmussen HS, Rasmussen CS, Macko J. VEGF gene therapy for coronary artery disease and peripheral vascular disease. Cardiovasc Radiat Med. 2002;3(2):114117.

30. Diabetes mellitus: a major risk factor for cardiovascular disease. A joint editorial statement by the American Diabetes Association; The National Heart, Lung, and Blood Institute; The Juvenile Diabetes Foundation International; The National Institute of Diabetes and Digestive and Kidney Diseases; and The American Heart Association. Circulation. 1999;100(10):1132-1133.

31. Katon WJ, Lin EH, Russo J, Von Korff M, Ciechanowski P, Simon G, Ludman E, et al. Cardiac risk factors in patients with diabetes mellitus and major depression. $\mathrm{J}$ Gen Intern Med. 2004;19(12):1192-1199.

32. Magda S. Rheumatoid arthritis vs. diabetes mellitus as risk factors for cardiovascular disease: the CARRE study. Maedica (Buchar). 2010;5(2):147.

33. Alexander CM, Landsman PB, Teutsch SM. Diabetes mellitus, impaired fasting glucose, atherosclerotic risk factors, and prevalence of coronary heart disease. Am J Cardiol. 2000;86(9):897-902.

34. Janghorbani M, Amini M, Tavassoli A. Coronary heart disease in type 2 diabetes mellitus in Isfahan, Iran: prevalence and risk factors. Acta Cardiol. 2006;61(1):13-20.

35. Nicolucci A, De Berardis G, Sacco M, Tognoni G. Primary prevention of cardiovascular diseases in people with diabetes mellitus: a scientific statement from the American Heart Association and the American Diabetes Association: response to Buse et al. Diabetes Care. 2007;30(6):e57; author reply e58.

36. Chou E, Suzuma I, Way KJ, Opland D, Clermont AC, Naruse K, Suzuma K, et al. Decreased cardiac expression of vascular endothelial growth factor and its receptors in insulin-resistant and diabetic States: a possible explanation for impaired collateral formation in cardiac tissue. Circulation. 2002;105(3):373-379.

37. Marfella R, Esposito K, Nappo F, Siniscalchi M, Sasso FC, Portoghese M, Di Marino MP, et al. Expression of angiogenic factors during acute coronary syndromes in human type 2 diabetes. Diabetes. 2004;53(9):23832391.

38. Khazaei M, Fallahzadeh AR, Sharifi MR, Afsharmoghaddam N, Javanmard SH, Salehi E. Effects of diabetes on myocardial capillary density and serum angiogenesis biomarkers in male rats. Clinics (Sao Paulo). 
2011;66(8):1419-1424.

39. Kota SK, Meher LK, Jammula S, Krishna SV, Modi KD. Aberrant angiogenesis: The gateway to diabetic complications. Indian J Endocrinol Metab. 2012;16(6):918930.

40. Jesmin S, Zaedi S, Shimojo N, Iemitsu M, Masuzawa $\mathrm{K}$, Yamaguchi N, Mowa CN, et al. Endothelin antagonism normalizes VEGF signaling and cardiac function in STZ-induced diabetic rat hearts. Am J Physiol Endocrinol Metab. 2007;292(4):E1030-1040.

41. Iemitsu M, Maeda S, Jesmin S, Otsuki T, Miyauchi T. Exercise training improves aging-induced downregulation of VEGF angiogenic signaling cascade in hearts. Am J Physiol Heart Circ Physiol. 2006;291(3):H12901298.

42. Al-Jarrah M, Jamous M, Al Zailaey K, Bweir SO. Endurance exercise training promotes angiogenesis in the brain of chronic/progressive mouse model of Parkinson's Disease. NeuroRehabilitation. 2010;26(4):369373.

43. Al-Jarrah M, Pothakos K, Novikova L, Smirnova IV, Kurz MJ, Stehno-Bittel L, Lau YS. Endurance exercise promotes cardiorespiratory rehabilitation without neurorestoration in the chronic mouse model of parkinsonism with severe neurodegeneration. Neuroscience. 2007;149(1):28-37.

44. Al-Jarrah M, Obaidat H, Bataineh Z, Walton L, Al-Khateeb A. Endurance exercise training protects against the upregulation of nitric oxide in the striatum of MPTP/ probenecid mouse model of Parkinson's disease. NeuroRehabilitation. 2013;32(1):141-147.

45. Melly LF, Marsano A, Frobert A, Boccardo S, Helmrich U, Heberer M, Eckstein FS, et al. Controlled angiogenesis in the heart by cell-based expression of specific vascular endothelial growth factor levels. Hum Gene Ther Methods. 2012;23(5):346-356.

46. Inoue $M$, Itoh $H$, Ueda $M$, Naruko T, Kojima A, Komatsu R, Doi K, et al. Vascular endothelial growth factor (VEGF) expression in human coronary atherosclerotic lesions: possible pathophysiological significance of VEGF in progression of atherosclerosis. Circulation. 1998;98(20):2108-2116.

47. Hicklin DJ, Ellis LM. Role of the vascular endothelial growth factor pathway in tumor growth and angiogenesis. J Clin Oncol. 2005;23(5):1011-1027.

48. Bieri M, Oroszlan M, Farkas A, Ligeti N, Bieri J, Mohacsi P. Anti-HLA I antibodies induce VEGF production by endothelial cells, which increases proliferation and paracellular permeability. Int J Biochem Cell Biol. 2009;41(12):2422-2430.

49. Breslin JW, Pappas PJ, Cerveira JJ, Hobson RW, 2nd, Duran WN. VEGF increases endothelial permeability by separate signaling pathways involving ERK-1/2 and nitric oxide. Am J Physiol Heart Circ Physiol.
2003;284(1):H92-H100.

50. Lal BK, Varma S, Pappas PJ, Hobson RW, 2nd, Duran WN. VEGF increases permeability of the endothelial cell monolayer by activation of $\mathrm{PKB} / \mathrm{akt}$, endothelial nitric-oxide synthase, and MAP kinase pathways. Microvasc Res. 2001;62(3):252-262.

51. Bates DO. Vascular endothelial growth factors and vascular permeability. Cardiovasc Res. 2010;87(2):262271.

52. Bates DO, Harper SJ. Regulation of vascular permeability by vascular endothelial growth factors. Vascul Pharmacol. 2002;39(4-5):225-237.

53. Bates DO, Hillman NJ, Williams B, Neal CR, Pocock TM. Regulation of microvascular permeability by vascular endothelial growth factors. J Anat. 2002;200(6):581597.

54. Suzuki J. Microvascular angioadaptation after endurance training with L-arginine supplementation in rat heart and hindleg muscles. Exp Physiol. 2005;90(5):763-771.

55. Czarkowska-Paczek B, Zendzian-Piotrowska M, Bartlomiejczyk I, Przybylski J, Gorski J. Skeletal and heart muscle expression of PDGF-AA and VEGF-A after an acute bout of exercise and endurance training in rats. Med Sci Monit. 2010;16(5):BR147-153.

56. Wu G, Rana JS, Wykrzykowska J, Du Z, Ke Q, Kang $\mathrm{P}$, Li J, et al. Exercise-induced expression of VEGF and salvation of myocardium in the early stage of myocardial infarction. Am J Physiol Heart Circ Physiol. 2009;296(2):H389-395.

57. Miele C, Rochford JJ, Filippa N, Giorgetti-Peraldi S, Van Obberghen E. Insulin and insulin-like growth factor-I induce vascular endothelial growth factor mRNA expression via different signaling pathways. J Biol Chem. 2000;275(28):21695-21702.

58. Han B, Baliga R, Huang H, Giannone PJ, Bauer JA. Decreased cardiac expression of vascular endothelial growth factor and redox imbalance in murine diabetic cardiomyopathy. Am J Physiol Heart Circ Physiol. 2009;297(2):H829-835.

59. Abaci A, Oguzhan A, Kahraman S, Eryol NK, Unal S, Arinc H, Ergin A. Effect of diabetes mellitus on formation of coronary collateral vessels. Circulation. 1999;99(17):2239-2242.

60. Li S, Culver B, Ren J. Benefit and risk of exercise on myocardial function in diabetes. Pharmacol Res. 2003;48(2):127-132.

61. Cohen MV, Yipintsoi T, Scheuer J. Coronary collateral stimulation by exercise in dogs with stenotic coronary arteries. J Appl Physiol Respir Environ Exerc Physiol. 1982;52(3):664-671.

62. Gielen S, Schuler G, Hambrecht R. Exercise training in coronary artery disease and coronary vasomotion. Circulation. 2001;103(1):E1-6.

63. Buttar HS, Li T, Ravi N. Prevention of cardiovascu- 
lar diseases: Role of exercise, dietary interventions, obesity and smoking cessation. Exp Clin Cardiol. 2005;10(4):229-249.

64. Hambrecht R, Adams V, Erbs S, Linke A, Krankel N, Shu
Y, Baither Y, et al. Regular physical activity improves endothelial function in patients with coronary artery disease by increasing phosphorylation of endothelial nitric oxide synthase. Circulation. 2003;107(25):3152-3158. 